\title{
دور الأثطة التربوية فى تنمية الهوية القومية دراسة ميدانية
}

\section{إعلاد}

د/ رشاد أبو المجد مصطفى

مدرس أصول التربية - كلية التربية بقنا

$$
\text { جامعة جنوب الوادي }
$$

rashadmostafa@edu.svu.edu.eg

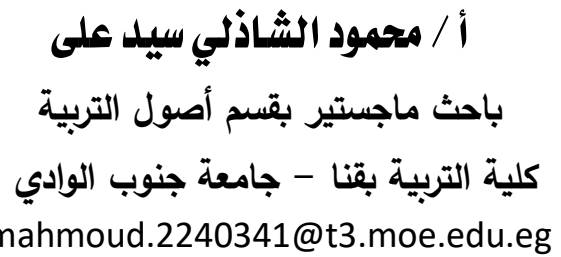

أ.د/ صبري الأنصاري إبراهيم

أستاذ أصول التربية- كلية التربية بقنا

$$
\text { جامعة جنوب الوادي }
$$

sabryibrahem@edu.svu.edu.eg

$$
\begin{aligned}
& \text { د/ آمال محمد إبراهيه } \\
& \text { مدرس أصول التربية - كلية التربية بقنا } \\
& \text { جامعة جنوب الوادي } \\
& \text { amlwane @yahoo.com }
\end{aligned}
$$




\section{دور الأنشطة التربورية فى تنمية الهوية القومية " دراسة ميدانية "}

\section{إعداد}

\section{د/ رشّاد أبو المجلد مصطفى}

مدرس أصول التربية - كلية التربية بقنا

$$
\text { جامعة جنوب الوادي }
$$

rashadmostafa@edu.svu.edu.eg

\section{أ / محمود الشاذلي سيلد على}

باحث ماجستير بقسم أصول التربية

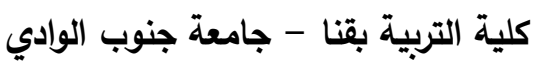

mahmoud.2240341@t3.moe.edu.eg
أ.د أدبري الأنصاري إبراهيم

أستاذ أصول التربية- كلية التربية بقنا

جامعة جنوب الوادي

sabryibrahem@edu.svu.edu.eg

د/ آمال محمد إبراهيي

مدرس أصول التربية - كلية التربية بقنا

جامعة جنوب الوادي

amlwane @yahoo.com

المستخلص : (المت

هدفت الدراسـة الحالية إلى التعرف على مفهوم الهويـة القوميـة وأهم التحديات التى

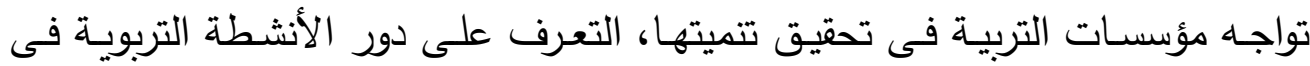
تتمية الهوية القومية، الوقوف على الواقع الفعلي لدور الأنشطة التربوية فى تتمية الهوية القوميـة مـن وجهـة نظـر طـلاب وطالبـات المرحلـة الإعداديـة فـى المـدارس التجريبيـة الحكوميـة للغـات فى محافظة قنا، وضـع تصور مقترح لتفعيل دور هذه الأنشطة فى تتمية الهويـة القومية لتلاميذ المرحلة الاعدادية ـ واعتمد الباحث على المنهج الوصفي التحليلي لوصف وتحليل واقع الأنشطة التربويـة فـى تتميـة الهويـة القوميـة، كمـا اعتمد الباحث على الاستبانة التى طبقت على عينة عشوائية ممثلة من ( A ( ) طالب وطالبة فى المدارس التجريبية للغات فى محافظة قنا ومراكزها، والتوصل إلى بعض المقترحات

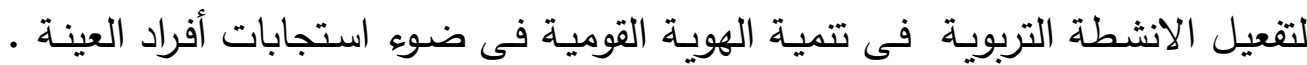
وأظهرت نتائج الدراسـة أن هنالك اتجاهًا حقيقًا نحو أهميـة ممارســة الأنشطة التربويـة

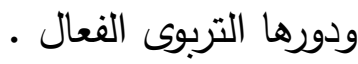
الكلمات المفتاحية : الأنشطة التربوية - الهوية القومية 


\title{
The Role of educational activities in the development of National Identity.(Field Study)
}

\author{
Dr. Sabri Al Ansari Ibrahim \\ Professor of Education \\ Faculty of education \\ South vally university \\ sabryibrahem@edu.svu.edu.eg \\ Dr. Amal Mohamed Ibrahim \\ Teacher of the fundamentals of \\ education- Faculty of education- South \\ vally university \\ amlwane@yahoo.com
}

\author{
Dr. Rashad Abul-Magd Mostafa \\ Teacher of the fundamentals of \\ education- Faculty of education \\ South vally university \\ rashadmostafa@edu.svu.edu.eg \\ Mahmoud Shazly Sayed Ali \\ Master Researcher Department of \\ education foundations- South vally \\ university \\ mahmoud.2240341@t3.moe.edu.eg
}

\begin{abstract}
:
The present study aimed to identify the concept of national identity and the most important challenges facing educational institutions in achieving their development, and to identify the role of educational activities in the development of national identity and to identify the actual reality of the role of educational activities in the development of national identity from the point of view of students and students of preparatory stage in experimental schools Governmental organization for languages in Qena Governorate, to develop a proposed vision to activate the role of these activities in the development of the national identity of students in the preparatory stage. The researcher also relied on the analytical descriptive approach to describe and analyze the reality of educational activities in the development of national identity. The researcher also relied on the questionnaire that was applied to a random sample of 180 students in experimental language schools in Qena governorate and its centers, Development of national identity in the light of responses of sample members. The results of the study showed that there is a real trend towards the importance of practicing educational activities and their effective educational role.
\end{abstract}

Keywords : educational activities - national identity

العدد الأربعون


مقدمة

تلعب الأنشطة التربوية دورًا كبيرًا فى تحقيق النمو السوى للتلاميذ، وتتمية شخصياتهم، وإشباع حاجاتهم الأساسية فى التعبيرعن الذات، وإمدادهم بالمهارات والخبرات التى تساعدهم فى مواجهة مواقف الحياة المختلفة والقيام بدور إيجابي تجاه القضايا والمشكلات التى تواجه مجتمعه ووطنهم والمساهمة فى حلها فى ظلى ظل المتغيرات العالمية، مما يؤدى الى ترسيخ الهوية، وتتمية قيم الانتماء لديهم • وتهدف التربية الحديثة عن طريق المدرسة إلى مساعدة تلاميذها على النمو السوى جسميًا وعقليًا واجتماعيًا وعاطفيًا وروحيًا حتى يصبحوا مواطنين صالحين مسئولين عن أنفسه ووطنهم، ويتفهوا بيئاته الطبيعية والاجتماعية والثقافية بكافة مستوياتها، ويتحقق ذلك كله من خلال التعليم وممارسة الأنشطة التربوية داخل المدرسة وخارجها ـ وتتاولت العديد من الدراسات العربية أهمية النشاط التربوى، وذكر" أحمد كامل الرشيدى " أن " النشاط التربوى " فى المرحلة الإعدادية يعد مجالًا خصبًا تتحقق فيه العديد من الأغراض التربوية منها : تعويد التلميذ الاعتماد على النفس، وإدراكه بأنه جزء من الجماعة التى ينتمى إليها، كما تسهح الأنشطة التربوية فى إتاحة الفرصة

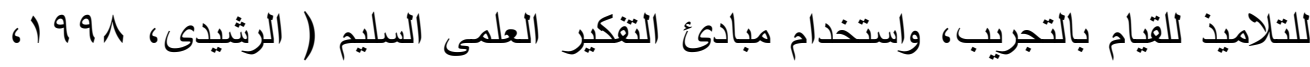
ص ص ص (1) ص كما أشارت دراسة " درية السيد البنا " إلى أن الأنشطة التربوية لها أهدافها التى

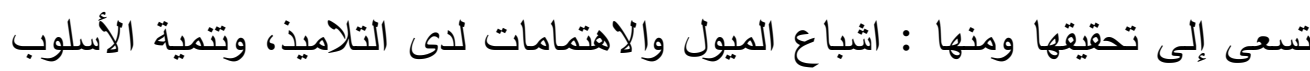
الديمقراطى، واحترام الفروق الفردية بين المتعلمين، وحل المشكلات التى تواجههم فى

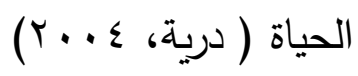

وبناء عى ذلك يرى الباحث ضرورة توجيه النشاط التربوى ليكتسب منه التلاميذ بعض القيم كالمحافظة على الملكية العامة، وترشيد الاستهلاك، وحماية البيئة من التلوث، والمحافظة على الموارد المائية، حيث يمكن بث العادات والسلوكيات المرغوبة بطريقة مباشرة من خلال جماعات الأنشطة التربوية المتنوعة . 
وقد أشارت دراسة " لطيفة ابراهيم خضر " إلى أهمية مرحلة المراهقة باعتبارها من

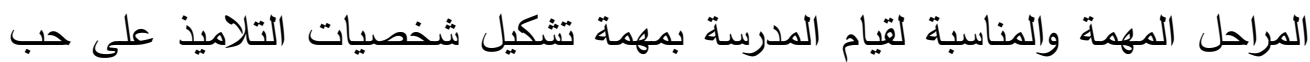

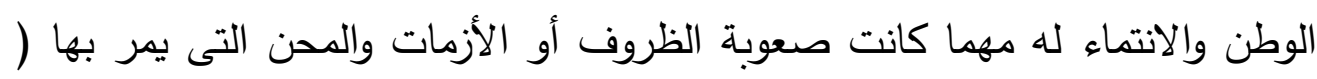

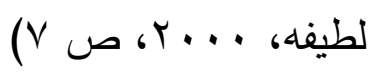
حيث تعد المرحلة الإعدادية مرحلة مهمة يجب أن يستغل فيها توجيه التلاميذ والاستفادة من البرامج التى تسمح بالتوجيه الفردى والجماعى، فتهيئ الفرص للتلاميذ لاكتشاف ميولهم واستعداداتهم عن طريق الملاحظة والعمل فى جماعات الأنشطة

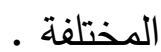

\section{مشكلة الاراسة}

يعد الحفاظ على الهوية القومية وتتمية الولاء والانتماء الوطنى من الموضوعات التى شغلت بال علماء النفس والاجتماع والسياسة، ومع التقدم التكنولوجى الهائل، وتحديات العولمة التى أصبحت أمرا واقعا فرض نفسه على العالم ومنه المتمع المصرى، والتى أصبحت تشكل بسلبياتها خطرًا على القيم الانسانية خاصة لدى بعض وصل شرائح الأطفال والثباب مما زادت الحاجة إلى ضرورة مواجهة سلبيات العولمة وليس

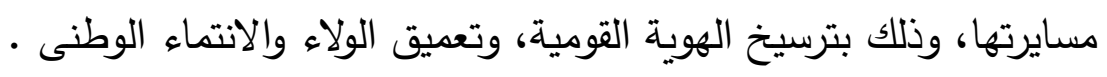
وفى الأونة الأخيرة انتشرت فى المجتمع المصرى العديد من الظواهر السلبية التى تتنافى مع معتقدات وقيم هذا المجتمع وتهدد بإضعاف الشعور بالانتماء الوطنى

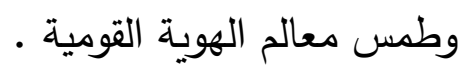
حيث أشارت دراسة " مجدة احمد محمود " إلى ضعف الانتماء وفقدان الأفراد لهويتهم يرجع ذلك إلى فقدان التواصل بالاخرين، وانتشار الأنانية والفردية، والسعى إلى الى درداء تحقيق الأهداف الذاتية، واجتاحت المصرى نزعة الشعور بالفردية ( مجدة، و191 ( ) وأظهرت نتائج دراسة "أسماء عبدالمنعم ابراهيم" أن هناك احساس بضعف نالتف الانتماء

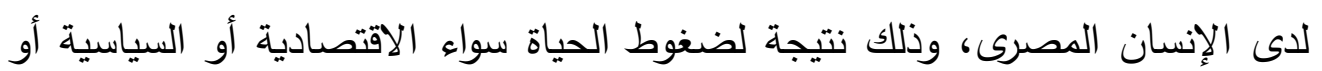
الاجتماعية، وهذه الضغوط تلعب دورًا مهمًا فى ظهور السلوكيات الضارة بين أفراد 
المجتمع، وتؤدى إلى اضطراب القيم، وانعدام روح الانتماء بين الافراد ( أسماء، () $9 \wedge \mathrm{V}$

كما أظهرت نتائج " السيد سعداوى اسماعيل " أن التلميذ يكتسب من خلال ممارسته للأنشطة المدرسية قيم العمل الجماعى وتحمل المسئولية والمناقشة الحرة والانتماء، كما يتدرب على القيادة والتبعية والمحافظة على المال العام ( السيد، (1991

وتعد المدرسة فى جميع مراحلها التعليمية من أهم المؤسسات التى تقوم بعملية

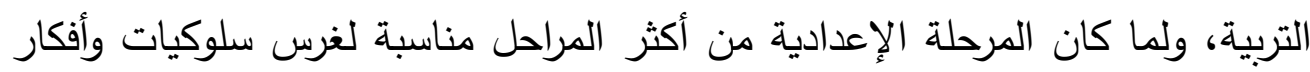
طيبة فى نفوس وعقول تلاميذها نظرا لأن طبيعة هذه المرحلة وخصائص الملتحقين بها يفرض أبعادا تستلزم الاهتمام بغرس وتتمية الاتجاهات الإيحابية والقيم الوطنية لدى تلاميذ هذه المرحلة، وهو الأمر الذى يستوجب الاهتمام المتزايد بالأنشطة التربوية باعتبارها الجزء المكمل للتربية المتكامل ، وهى الوسيلة التى تساعد فى اكتساب التلاميذ المفاهيم والمهارات المطلوبة واستيعابها، وتتمية الشعور بالانتماء والولاء الوطنى، والاعتزاز بالهوية القومية لديهم. من هنا جاءت فكرة هذه الدراسة للبحث دور الأنشطة التربوية فى تتمية الهوية القومية لتلاميذ تلك المرحلة . تساؤلات الدراسة

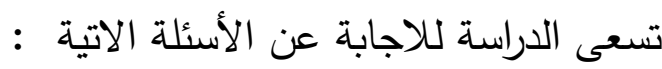
ا- ما مفهوم الهوية القومية ؟ وما التحديات التى تواجه مؤسسات التربية فى تحقيق تنميتها ؟ r- ما دور الانشطة التربوية فى تتمية الهوية القومية ؟

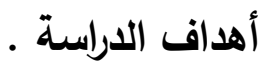

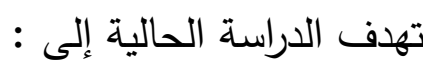
ا - التعرف على المقصود بالهوية القومية، وأهم التحديات التى تواجه مؤسسات التربية فى تحقيق تنميتها. 
r- الوقوف على دور الأنشطة التربوية فى تتمية الهوية القومية لتلاميذ المرحلة الإعدادية . الم

r- وضع تصور مقترح لتفعيل دور الأنشطة التربوية فى تتمية الهوية القومية لتلاميذ أهمية الدراسلة الإعدادية.

ا- إن الدراسة تتناول عنصرا أساسياً من عناصر الحياة المدرسية وهو النشاط التربوى، وما يمثلك من أهمية كبيرة فى نجاح العملية التعليمية والتربوية . ץ- تتناول الدراسة مرحلة تعليمية على قدر كبير من الأهمية وهى المرحلة الإعدادية

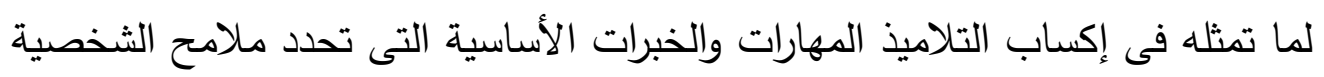
القومية .

r- تقيد هذه الدراسة من خلال ما تقدمه من نتائج للقائمين على شئون التربية والتعليم عامة، والمهتمين بالأنشطة التربوية خاصة فى تحسين واستغلال هذه الأنشطة . منهج الاراسة :

اعتمد الباحث على المنهج الوصفى لمناسبته لطبيعة الدراسة، وذلك للتعرف على دور الأنشطة التربوية فى تتمية الهوية القومية بالنسبة لتلاميذ المرحلة الإعدادية،

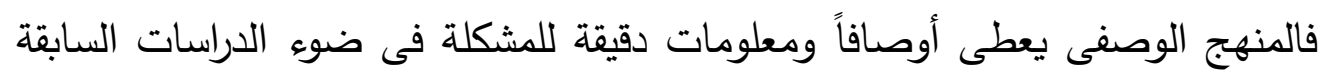

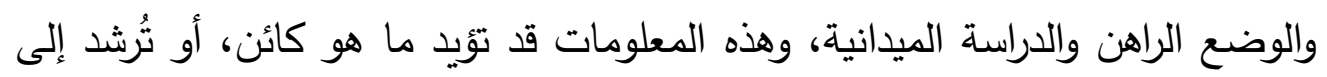
سبل التغيير أو التعديل أو التطوير إلى ما ينبغي أن يكون عليه ، وهذا هوانها هو الهدف

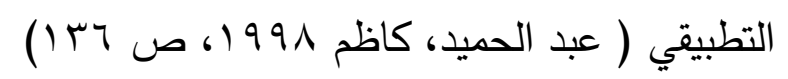
أدوات الدراسة :

تصميم استمارة استبيان بهدف التعرف على دور الأنشطة التربوية فى تتمية الهوية القومية لتلاميذ المرحلة الإعدادية . حدود الاراسة :

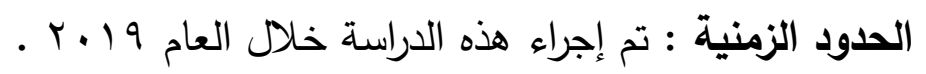


الحدود المكانية : تم تطبيق أداة الدراسة على عينة من المدارس التجريبية الحكومية للغات، المدارس التى اكتملت بها المرحلة الإعدادية بمحافظة قنا ومراكزها . الحدود البثرية : تم تطبيق أداة الدراسة على عينة عشوائية من طلاب وطالبات

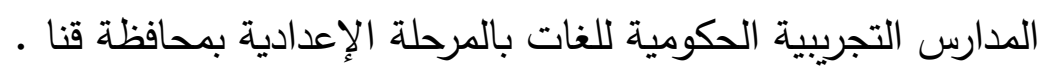
الارراسات السابقة

1- دراسة محمد حسنين عبده (999 199) : استهدفت التعرف على أنماط الأنشطة التربوية اللاصفية التى يجب أن تتواجد وتمارس بالفعل فى مدارس التعليم الأساسي،

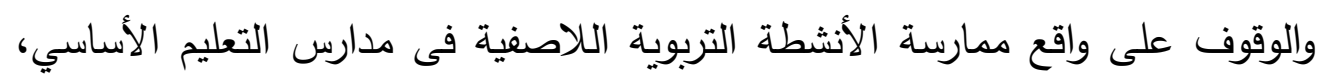
وكذلك التعرف على أهم المعوقات التى تعوق ممارسة التلاميذ للأنشطة التربوية، وتكونت عينة الدراسة من (7^) من موجهى ووكلاء النشاط ومعلمى اللغة العربية

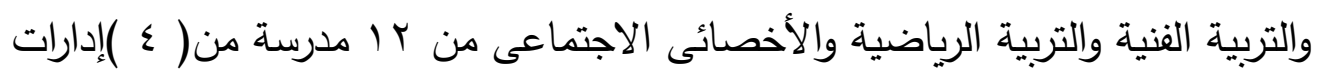
تعليمية، وتمثلت أدوات الدراسة فى استبيان من إعداد الباحث للتعرف على معوقات ممارسة الانشطة التربوية، واستخدم الباحث المنهج الوصفى التحليلى، وأظهرت النتائج

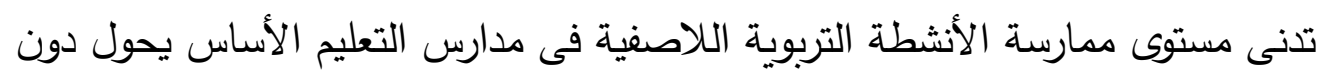
تحقيق الوظيفة الاجتماعية لتلك المدارس، كما أظهرت أن هناك فرقا شاسعا بين واقع لـانع ممارسة تلك الأنشطة بمدارس التعليم الأساسي وما يجب أن يكون عليه واقع تلك لكانكان

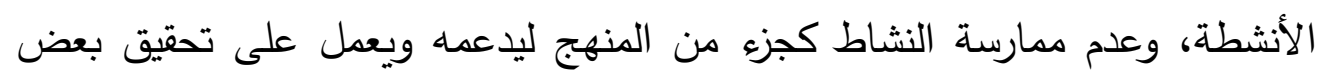
الأهداف الأنشط،

r - دراسة عايدة عباس واخرون (9 9 V I ) : هدفت إلى التعرف على اكتشاف مدى

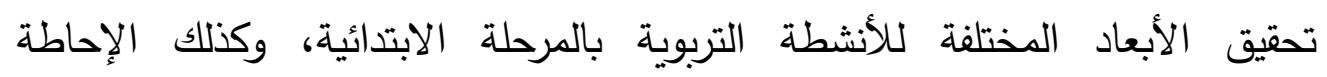
بالمشكلات والمعوقات التى تواجه الأنشطة التربوية الحرة والوصول إلى الحلول

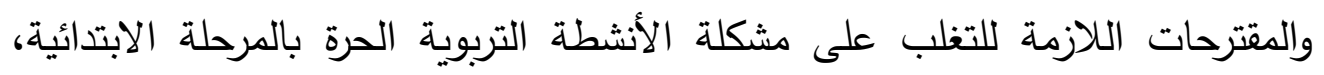
واستعانت الدراسة بالمنهج الوصفى من خلال إتباع النمط المسحى لجمع البيانات

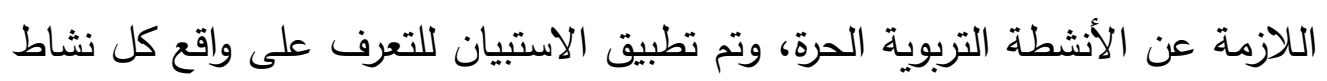
على حدة، وتم تطبيق أدوات الدراسة على مشرفات الأنشطة التربوية الحرة بالمدرسة التحنية 
الابتدائية فى مدارس محافظات القاهرة والثرقية والمنيا، وتوصلت نتائجها إلى وجود خطة فعلية للنشاط الفنى فى المدرسة، ولكن يكون القصور فى عدم توافر أماكن مناسبة، وفى استثمار الامكانات المتاحة، وكذلك عدم وجود خطة واضحة للنشاط فى أذهان القائمين عليه من مستوى الإدارة التعليمية إلى موجهين والمعلمين وأولياء الأمور والتلاميذ، ووجود العديد من المعوقات التى تحول دون ممارسة التلاميذ للأنشطة التربوية الحرة بالمرحلة الابتدائية .

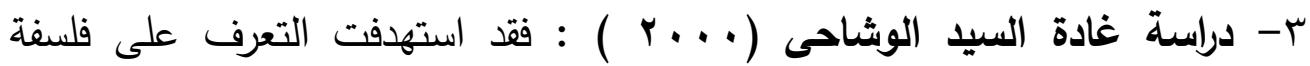
النشاط التربوى وأهميته فى تتمية الجانب الاجتماعى للفرد بالمدرسة، وكذلك التعرف على واقع ممارسة الأنشطة التربوية فى التعليم الثانوى وأثر ممارسة الطلاب للأنشطة

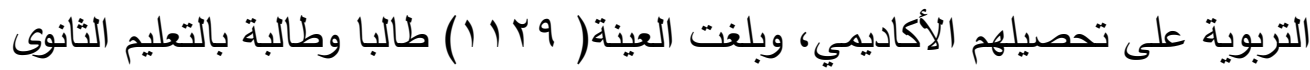

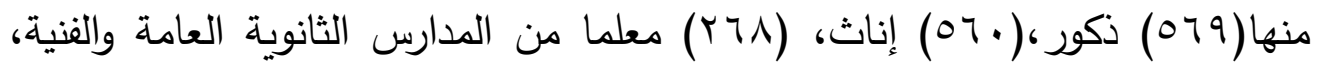
واستخدمت الباحثة المنهج الوصفى التحليلى، وتوصلت نتائجها إلى أن الأنشطة التربوية تستطيع تحويل الفلسفة الاجتماعية للمجتمع المصرى إلى واقع عملى داخل المدارس المصرية إذا ما توافرت لها الامكانيات المادية والبشرية المناسبة، وأحسن تخطيطها وتنفيذها وتقويمها، وبذلك تسهم بدور كبير فى تحقيق الأهداف الاجتماعية للتربية بالمرحلة الثانوية .

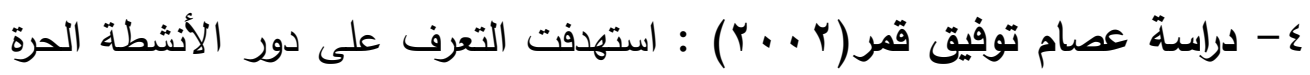

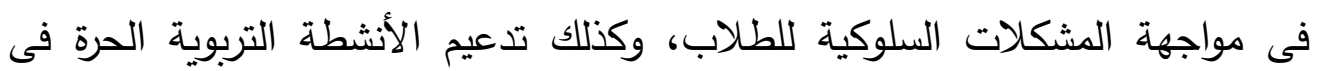
مواجهة المشكلات السلوكية للطلاب، وشملت العينة الدراسة (· (1) من عدد من المدارس الثانوية بمحافظة المنيا والقاهرة والاسكندرية، واستخدم الباحث المنهج الوصفى واستمارة استبيان للتعرف على دور الأنشطة التربوية فى مواجهة المشكلات السلوكية،

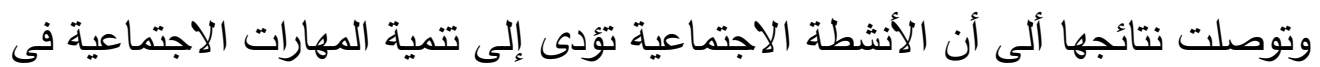
التعامل مع الاخرين، وتنفيذ معسكرات خدمة عامة تتمى روح التعاون بين الطلاب، وتقوى العلاقة بين المدرسين والطلاب عن طريق اشتراكهما معا فى ممارسة بعض المسابقات ذات الطابع الاجتماعى وتؤدى الأنشطة الرياضية إلى استثمار طاقات 
وأوقات فراغ الطلاب عن طريق إقامة المسابقات والمباريات الرياضية وتوعية الطلاب

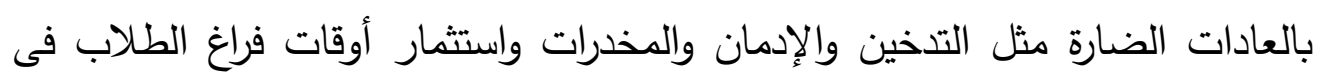
ممارسة الرياضة بأنواعها المختلفة . ماندان

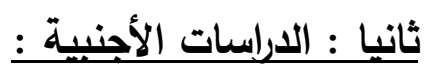

- دراسة ( joseph 2000 ) هدفت إلى التعرف على العلاقة بين مشاركة الأطفال والمراهقين فى الأنشطة اللاصفية ونماذج السلوك غير الاجتماعى فى الفترة من مرحلة الطفولة حتى مرحلة البلوغ بتقليل حجم السلوك غير الاجتماعى بالنسبة للأطفال والمراهقين، واشتملت عينة الدراسة على(790) تلميذ فى سبع مدارس حكومية

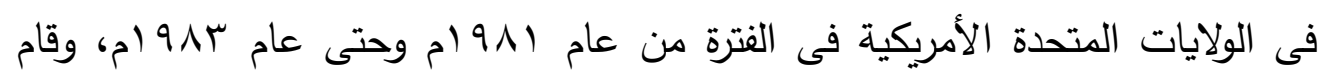
الباحث بإجراء مقابلات شحصية مع أفراد من تلاميذ الصف الرابع والسابع والثانى عشر، وتوصلت نتائجها إلى الطلاب المشاركين فى الأنشطة اللاصفية أقل تسربا من

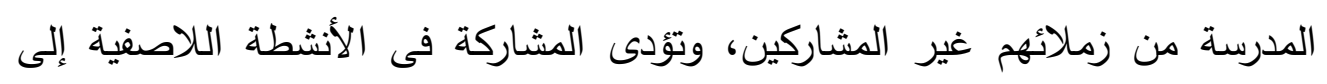
تحقيق التوافق الإيجابي للطلاب مرتفعى المخاطرة، وتؤدى المشاركة فى الأنشطة

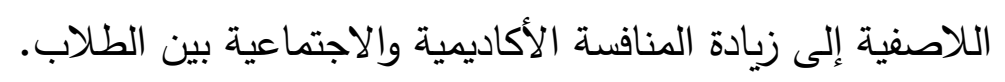

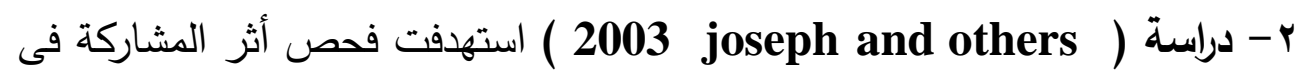
الأنشطة اللاصفية على تحقيق النجاح الأكاديمى للطلاب على المدى البعيد والوقوف

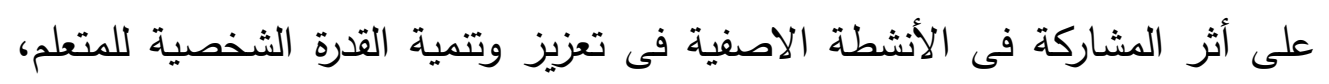
مثل : تحمل المسئولية والمبادرة والتى تمهد الطريق إلى النجاح والتوفيق الأكاديمى أمام الطلاب فيما بعد تخرجهم من المدرسة الثانوية وشملت عينة الدراسة 790 طالبا فى ولى التى الصفوف من السابع حتى الثانى عشر وتم تطبيق مقاييس تحدد القدرات والامكانات

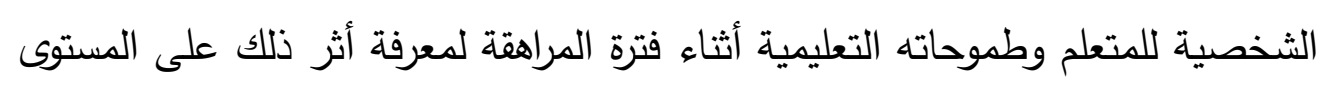

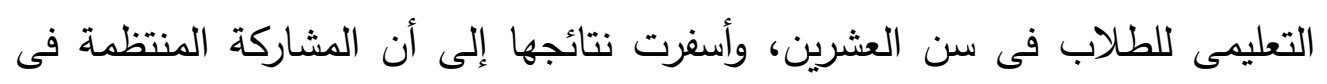

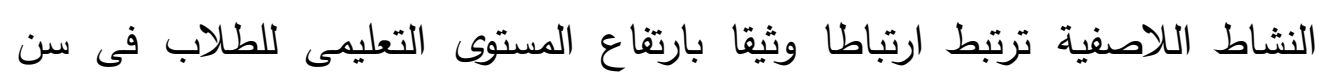
العشرين، وأن هناك علاقة موجبة وتفاعلية بين المستوى التحصيلى من ناحية

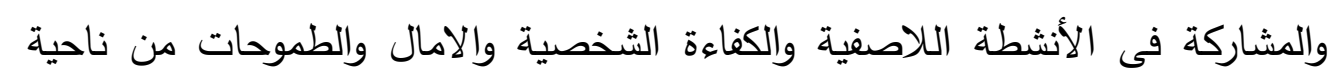


أخرى، تؤدى المشاركة فى الانشطة اللاصفية إلى تنمية قدرة المتعلم الشخصية وقدرته على تحمل المسئولية واكتساب القدرة على المبادرة الذاتية . r- دراسة ( 2005 mulligan ) هدفت إلى تحليل الدراسات البيئية المدرسية منذ الطفولة المبكرة، وتوضيح مدى استعداد المدارس، وكذلك الحد الفعلى للمشاركة الأسر فى نشاطات البيئة فى مدارس الحكومية، وتحديد مدى العلاقات الأسرية داخل الأسرة كالعلاقات الوالدية، ومدى تأثيرها على أداء الطلاب فى الأنشطة المدرسية البيئية، ومعرفة مدى مساهمة الأسرة فى نشر أفكار طيبة عن الأنشطة المدريسية، وتقديم المقترحات حول التبادل الفكرى بين الأسرة والمدرسة، وخاصة قيما يتعلق بالأنشطة

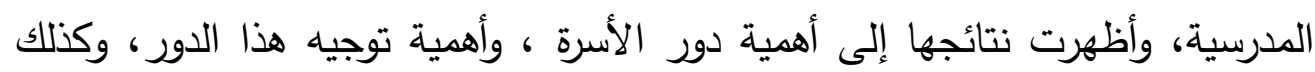

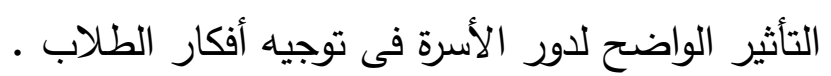
مصطلحات الاراسة : أ- الأنثطة التربويـة .

تعددت تعريفات الباحثين حول مفهوم النشاط التربوى ومن بين هذه التعريفات : - تعريف " رزق حسن عبد النبى " : "هو كل نشاط إيجابي يقوم به المعلم أو المتعلم أو كلاهما معا، متضمنا ذلك الجهد العقلى والبدنى المبذول، بحيث تشبع ممارسته الحاجات الجسمية والنفسية والاجتماعية والمعرفية ، وتتحقق فيه الاهداف التربوية

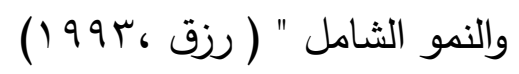
ويتصمن النشاط التربوي بذلك مجالات متعددة ثقافية واجتماعية وفنية ورياضية، وبذلك تكون جميع مجلات النشاط متداخلة ومتكاملة ويصعب الفصل بينها؛ لأنها تتناول تكوين التلميذ فى جميع جوانب شخصيته، وشخصية التلميذ وحدة متكاملة لاتقبل التجزئة .

- ويقصد بالأنشطة التربوية أنها " مجموعة الأنشطة الهادفة التى تتمى شخصية التلميذ فى المجالات الفنية والرياضية والاجتماعية، وتلبي رغباته وميوله، يمارسها

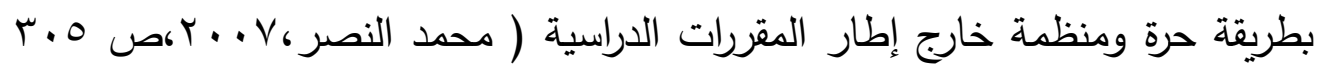


- ويعرف الباحث الأنشطة التربوية تعريفًا اجرئيًا بأنها : كل نشاط حر يمارس

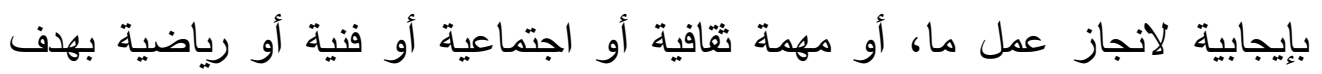
اكساب التلاميذ الخبرات والمهارات المختلفة التى تساعد فى تتمية القيم؛ وتقوى لديهم الاحساس بالولاء والانتماء لوطنهم والاعتزاز بهويتهم، وبذلك تساعد على تحقيق النمو

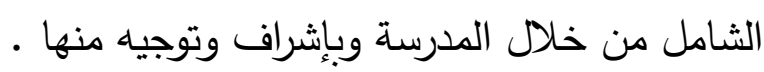

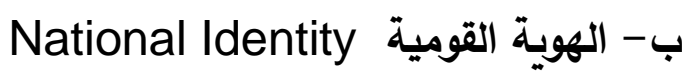
يرى "عدنان حسين "أن" الهوية القومية لم تعد مجرد شعور غريزي بالانتماء إلى

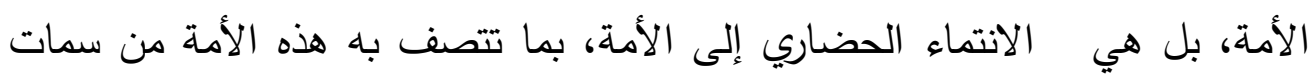
سياسية واجتماعية وثقافية وإنسانية "هوبية

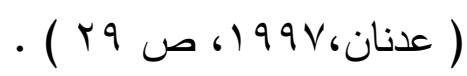

ويقول " السيد يس " إن الهوية القومية هي " السمات النفسية والاجتماعية والحضارية لأمة ما ، والتي تتسم بثبات نسبى، والتي يمكن عن طريقها التمييز بين هذه الأمة

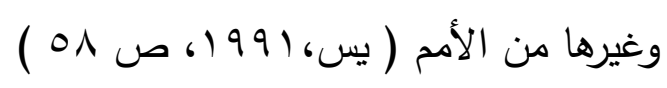

- ويعرف الباحث الهوية القومية بأنها : مجموعة القيم والصفات الاجتماعية والثقافية والحضارية ، التي يتصف بها الفرد أو المجتمع، والتي تؤكد الإحساس لاى الأفراد

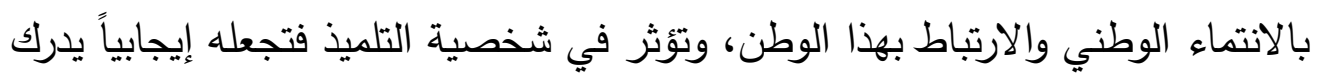

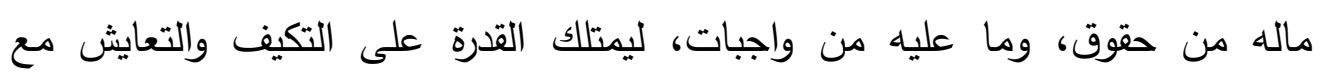

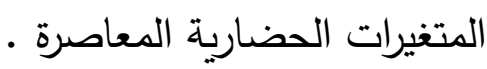
الفصل الأول : مفهوم الهوية القومية ، أهم التحديات التى تواجه مؤسسات التربية

فى تحقيق تنميتها. أولا ) مفهوم الهوية القومية تهيت تلهيتة يرى سعيد إسماعيل الهوية القومية ت تعنى كمفهوم بأنها " مجموعة من السمات

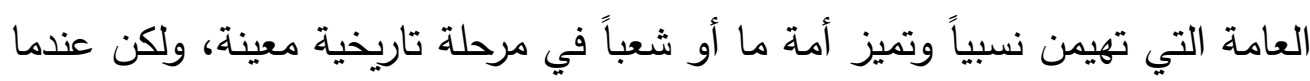
نرى السمات متأصلة في التركيب العقلي النفسي ذاته وهى ثابتة فيه، والمفهوم التاريخي يرى أن الهوية القومية بأنها فقط طرق تفكير وسلوك وشعور متماثلة ومهيمنة ونسبية 
وتاريخية، أنها استجابات يعايشها عن طريق النشأة الاجتماعية وليست رداً غريزياً

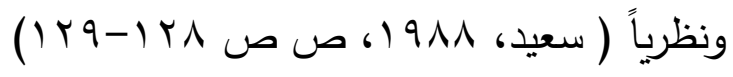

ويتفق مـع ذلك تعريـف " محمــ علــى نصـر " فيقصــ بالهويـة القوميـة "السـمات والخصائص التي يتمسك بها مجتمع من المجتمعات، وتميزه عن غيره من المجتمعات،

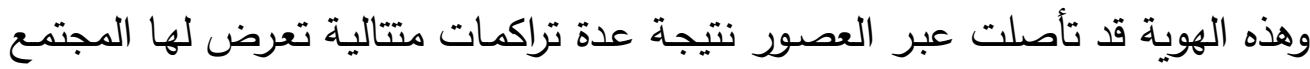
وتتمثل في جانبين: هما الجانب المـادي بمـا تضـمن مـن معارف ومعلومـات وفنون واكتثـافات واختراعـات وابتكـارات، والجانب المعنوي: الذي يتضـمن عـادات المجتمع

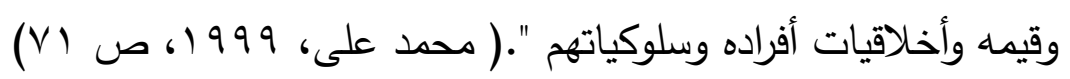
ويرى " Barakat" أن المقصود بالهوية القومية المشاركة في عناصر أساسية تحدد شخصية وتوجهات الأفراد من حيث احتياجاتهم المشتركة واهتماماتهم وأهدافهم ، كما Barakat 1993 p 32-33 ( تطوي على أهمية الاختلافات بين أفراد الهوية الواحدة.

ويعرف كل من " Keillor ,Bruce \& Tomas Hult " الهويـة بأنها " مجموعة المعاني والمفاهيم التي تمتلكها ثقافة معينـة وتميزهـا عن غيرهـا من الثقافات " فبنـاء الهويـة يأخذ فى الاعتبار كل نقاط التماثل والتوافق، وأيضـا نقاط الاختلاف والتباين،

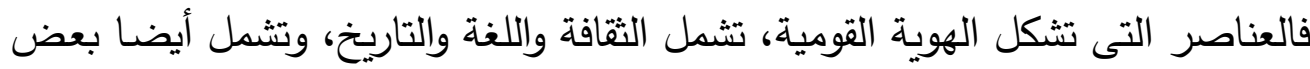
الاختلافات كالقبيلة والاختلافات الدينية ( Keillor ,Bruce 1999 p65 ) ومن هنا يوضح سويف أن الهوية القومية " هى الذات كما تنشأ فى إطار حضارى بعينه، مرتبط بموقع جغرافى بعينه، فالأساس العلمي للهويـة القومية من حيث تكوينها

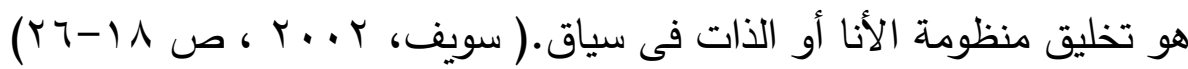
وينتهي فاروق يوسف إلى أن الهوية القومية مثلها مثل أى حقيقة اجتماعية، فهى حقيقـة عقليـة وليســت موضـوعية يبنيهــا أفـراد المجتمـع بعقـولهم ونتيجــة لتجــاربهم الاجتماعية والثقافية المختلفة ثم يتصرفون على هداها، ومن هنا فقد تتعرض هذه الهوية

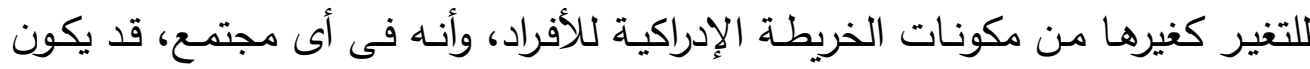
هنالك أكثر من هويـة، ولكن قد تكون احداها هـى السائدة وتكون الباقية هي الكامنـة،

$$
\text { العدد الأربعوذ }
$$




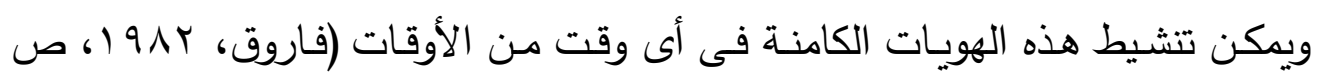

وتلخص ثريا البدوي إلى أن المقصود بالهويـة القومية توفر مجموعة من المكونات

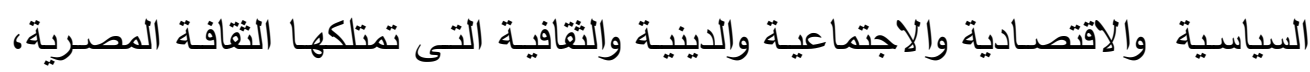
والتى تميزها عن غيرها من الثقافات وتحفظ لها شخصيتها فى عصر العولمة ( ثريا، (Orq מ

وفى ضوء مـا سبق عرضـه من المفـاهيم يتضـح أن مفهوم الهويـة القوميـة ينطوي

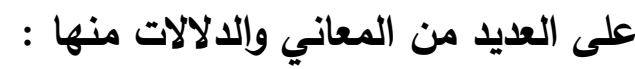

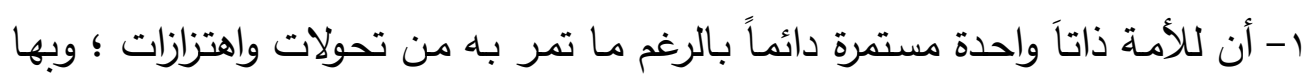
تتميز وتنفرد عن غيرها من الأمم. r- أنها تعبير عن ذاتها الجماعيـة أو الرمـز الذي يجتمـع عليـه كل أفرادهـا انتمـاء

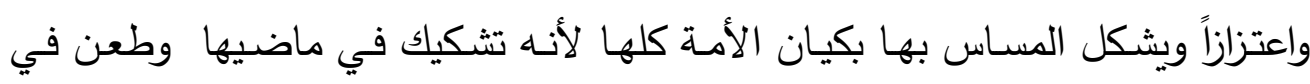
حاضرها، وبأس من مستقبلها . r- أن الهوية القومية هي الرمز أو القاسم المشترك أو النمط الراسخ الذي يميز أمة أو

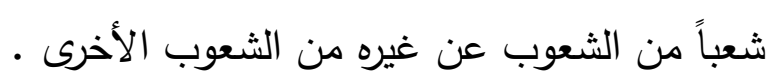

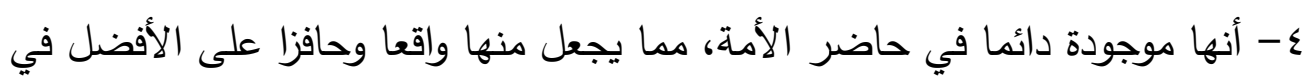

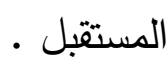
ه- أنها الضمير الجماعي للأمة ، ومن ثم لها وحدها الحق في تعديلها وتطويرها وفق شروط موضوعية حرة . ب- أهم التحديات التى تواجه مؤسسات التربية فى تحقيق تنميتها . أولا : التحديات الخارحية : أفم ا - العولمة :

يُعـد مفهوم العولمـة مـن المفـاهيم التي ازداد الحـديث عنهـا، حيث لاقت اهتمامـا

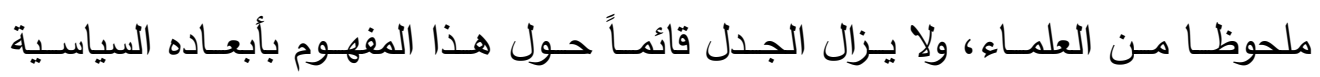
والاقتصادية والاجتماعية المختلفة . 
وتعرف العولمسـة بأنها " وعى وإحسـاس الأفراد في كل مكان بأن العـالم ينكمش ويتقلص ومن ثم تتضمن العولمة تخيل أن البشرية قد أصبحت أكثر ترابطا بفعل وسائل

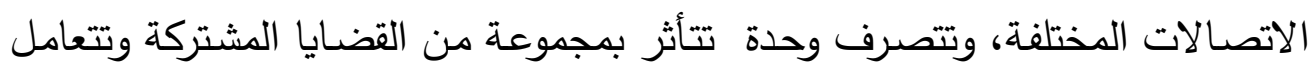

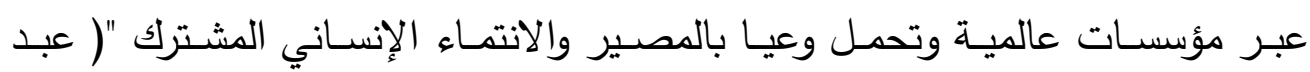

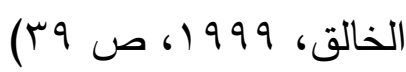
ويرى البعض الآخر العولمـة " ظـاهرة عالميـة جديدة تولدت من تراكم مجموعـة من العوامل، أهمها العوامل التكنولوجية التي تؤدى إلى إحداث خلل وتفكيك في العلاقات

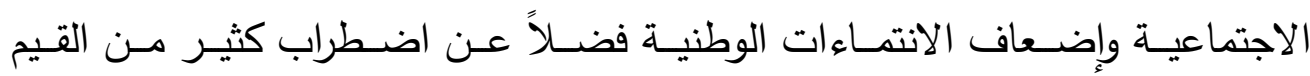

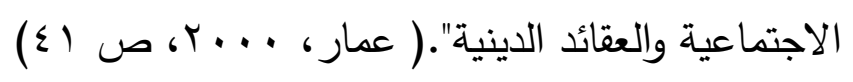
ويعرفها فيسكول وآخرون بأنها" التغيرات التي تصاحب العلاقات التاتئ الدولية والتي أدت

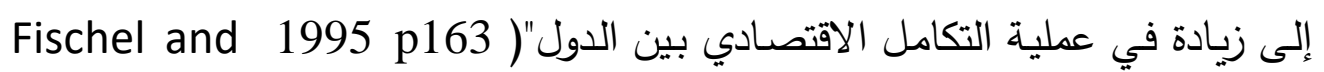
( others فمع بداية القرن الثامن عشر وجدنا أن معظم أوربا الغربية قد أدركوا أهمية اندماج وانصهار السياسة والثقافة معا في بوتقة واحدة، من أجل تحقيق نوع من وحدة وتماسك وجك الهحف، كى يستطيعون تكوين وتأسيس هويتهم الخاصة بهم، وهذا بدوره يؤدى المفاهيم

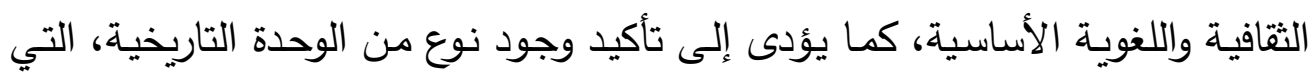
بدورها أدت إلى قيـام هذه الهويـة الأوربيـة، ومثل هذه الخطـوة يمكن أن تـدرك أنها البدايات الأولى لوجود ما يعرف بالعولمة.

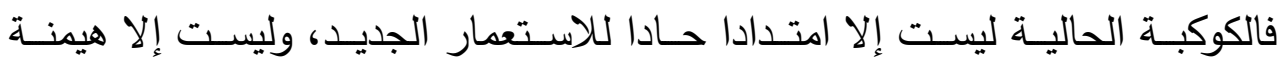
للرأسمالية الأوربية والأمريكية على بقية دول العالم، ولهذا فهى تسعى إلى القضاء على إلى

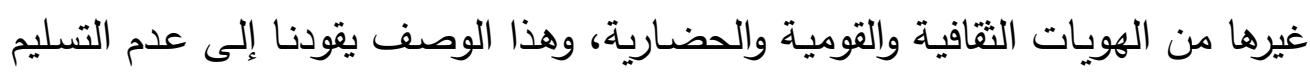

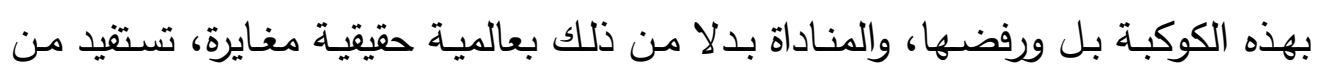
التقدم التكنولوجي الهائل لصنع عالم واحد كبير ، لا يقوم على الهيمنة، وإنما على حوار

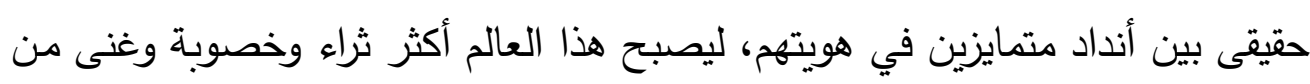
عالم تسوده هوية السوق الرأسمالية . 
ومـع التقــدم الصــاعي والتكنولـوجي السـريع فـي نهايـات القـرن العشـرين وتطـور

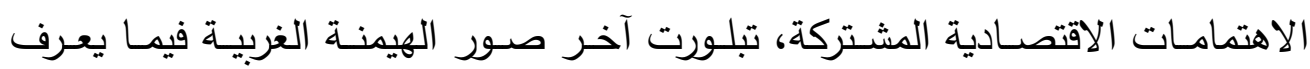

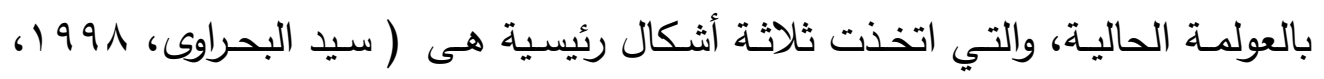
$:(\varepsilon r q$ - العولمة الاقتصادية :التي أصبحت واقعا ملموسا الآن، يتجلى في سيطرة رأس المال على مقدرات الشعوب بصرف النظر عن كونه في يد دولة أو أفراد . - العولمة السياسية : تمثلت في محاولة إيجاد نظام سياسي موحد لجميع الدول في

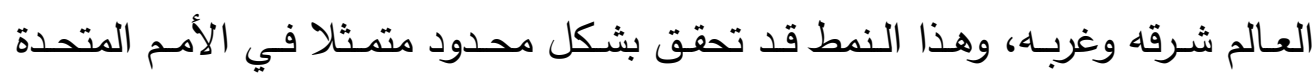
والسيطرة الأمريكية عليها، أو في القانون الدولي، ومحاولات قيام الدول الكبرى بدور الشرطي المنفذ لهذا القانون • - العولمة الثقافية : تمثلت في محاولة إيجاد نمط ثقافي موحد لدول العالم وهو ما لم

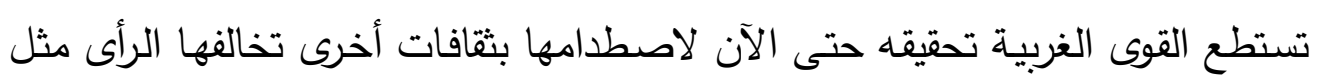

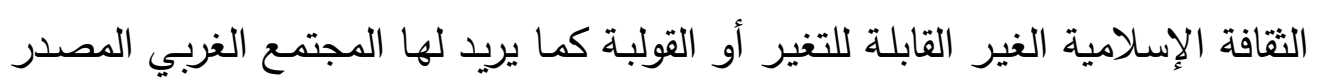
للعولمة . - الإن ويعد البعد الثقافي والاجتماعي للعولمة من أخطر أبعادها، فهي تعني إثـاعة قيم ومبادئ ومعايير ثقافة واحدة، وإحلالها محل الثقافات الأخري ؛ مما يعني تلاشي القيم والثقافـات القوميـة، وإحـال القيم الثقافيـة للبلاد الأكثر تقدما محلها، وخاصـة أمريكـا وأوربا، الأمر الذي ينعكس علي الهوية الثقافية العربية . ثانيا : التحديات الاخلية : إن هناك كثير من مؤسسات التربية مازالت في إعادة إنتاجها، ليس فقط في مجال

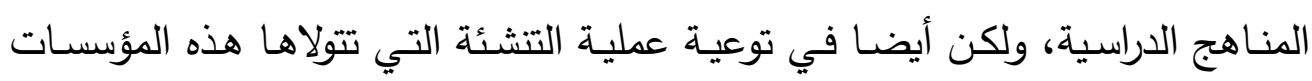
ذاتها باقتسامها أبناء المجتمع ما بين تعليم اللغة العربية وتعليم لغات أجنبية، وتعليم

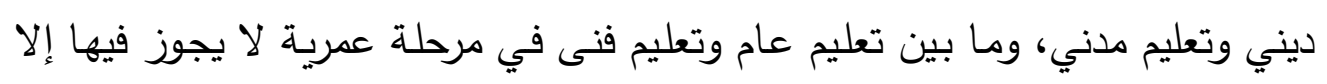


إعطاء قدر مناسب من المعرفة والعلوم والفنون والآداب للجميع مما يمكن من خلق المواطن الصالح الذى لديه قدر من الثقافة وفهم شخصية المجتمع • وتتجم أزمة الهوية القومية عن التحولات العميقة داخل المجتمع، نتيجة الانتقال من النسق الاجتماعي التقليدي إلى نسق أكثر حداثة وحضرية، ومن هنا تثار قضية الولاء ونوعية القيم الموجهة للسلوك ، ونو والطائفية، تلك الانتماءات التي تتجه إلى الاختفاء خـلال حركـة التحـول الإنمـائي لتحل محلهـا ولاءات وانتمـاءات جديـدة للدولـة القوميـة

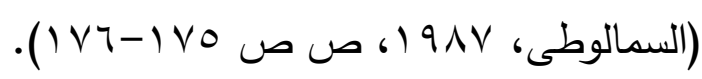
وتتجسد أزمـة الهوية القومية عند إلقاء نظرة على الثـارع المصري حيث اضطراب حركة المرور وسعى كل راكب فى الحصول على ما ليس بـه حق، وإن من مظاهر

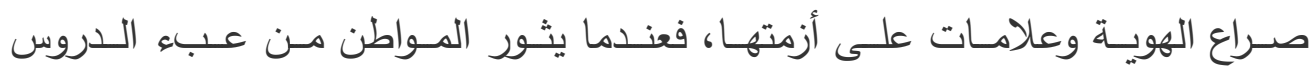
الخصوصية وارتفاع الأسعار وعدم انضباط المرور ، ويكيل النقد للحكومة، متتاسياً أنه أنه

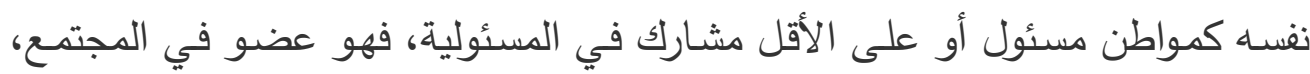

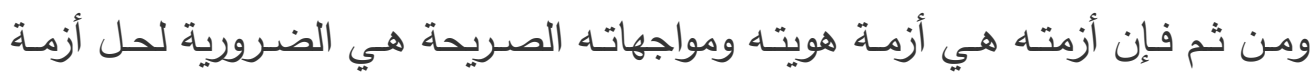

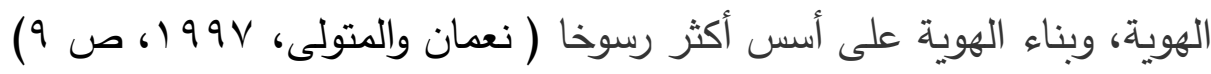

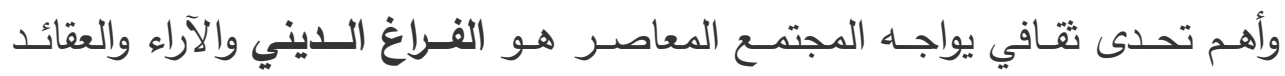

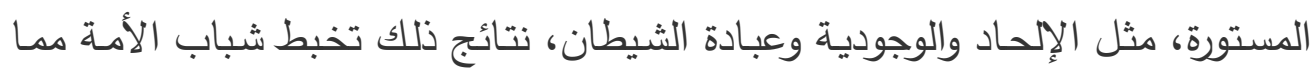
يدفع بهم إلى عضوية الجمعيات السرية كانت أو دينية والتي تتخذ من الدين عباءة لها. كما أن البيئة الاجتماعية تحاط بثقافات متردية، قد تفرغ العقلية الثقافية من وعيها بذاتها نتيجة مفاهيم خاطئة تنتشر وتتراكم فتسبب عدم الثـعور بالانتماء لدى أفراد

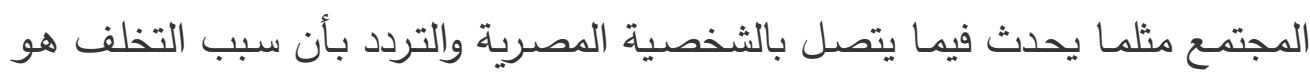

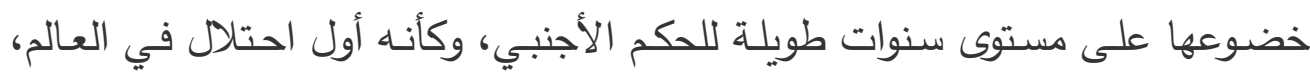

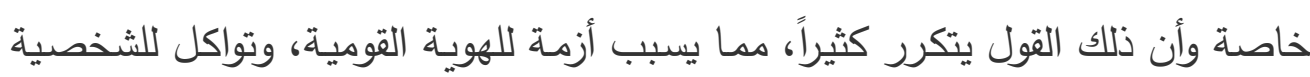

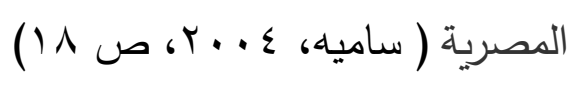

كما تقوم وسـائل الإعلام من خـلال البـ الواسـع بدور مركزي في اختراق منظومـة

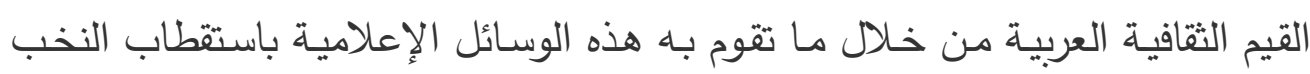


المثقفــة لتـرويج لفكـرة العولمــة وأيــلوجيتها ،عبـر الحــارات ونشـر نتـائج المـؤتمرات والندوات، حيث يتم تكثيف جهودهم من أجل إعادة تشكيل الرأى العام العربي والعالمي وجي

فمن خـلال وسـائل الإعـلام المختلفـة (صـافة ، إذاعـة ، تلفزيون ، إنترنت وغيرهـا) تسـى الدول الغربيـة إلى الهيمنـة على الهويـة الثقافيـة العربيـة والإسـلامية من خـلال

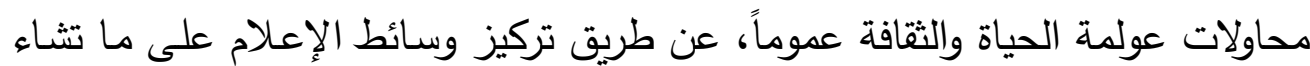
من القيم ، وإهمالها لما تشاء ، وبالتالي سعيها لفرض ثقافة بذاتها، وهذا ما يجري بوعي من قبل من يملك هذه الوسائط، وبدون وعي من قبل المستقيد .

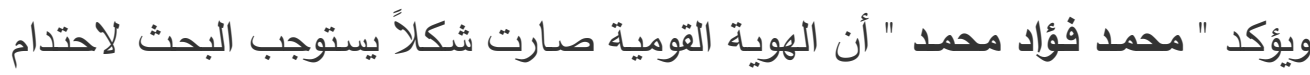

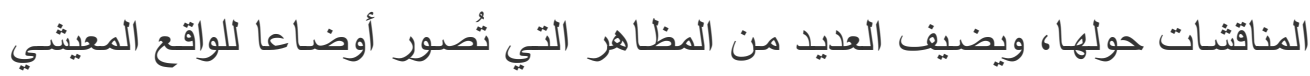

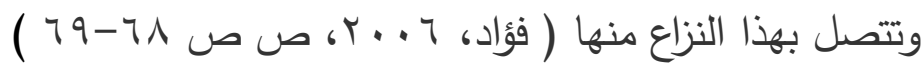
- الإقبال الكبير على نمـاذج الاستهلاك الوافدة لا من حيث أنها أكفأ وأجود، ولكن مـن حيث أنها صـارت مفعدـة بقيم تتعلق بـالتطور والتقدم والحضـارة والحداثة .

- قراءة الصحف والاهتمام بأخبار أوربا والغرب بوصفها الأخبار العالمية أكثر

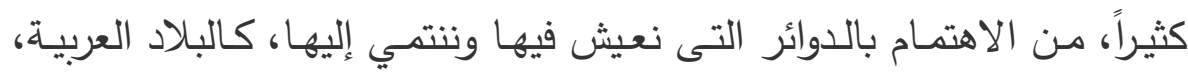
البلاد الإسلامية، والبلاد الأفريقية .

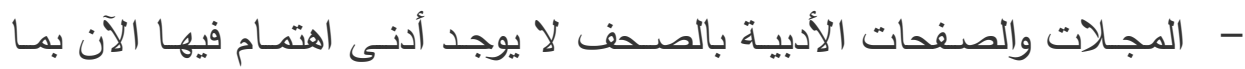

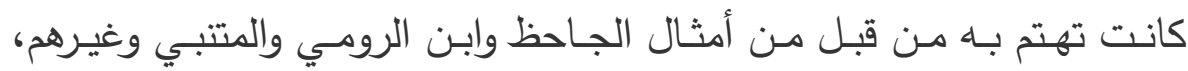
وغلبت اهتمامساتهم بحركة الأدب العربي الأوربي حديثًا وقديماً، حتى صـار

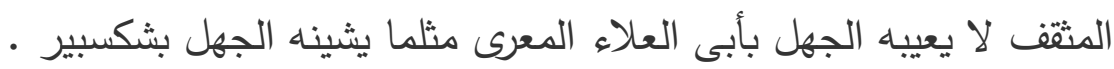
- المصطلح السياسي والفكري صـار يميل إلى استخدام الألفاظ المحايدة التي لا لاءئل

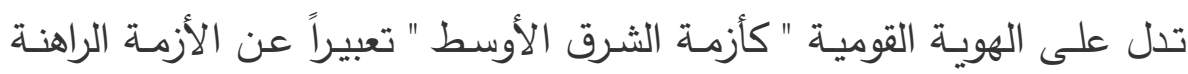
وكلفظ " التراث " تعبيراً عن الإسلام والقبطية . 
- لغـة وسـائل الإعـلام تتمو فيها الألفاظ غير العربيـة بالنسبة لحوائج المعيشـة القومية، وتترقق حروف اللغة وتتآكل حتى كادت تتطمس حروف بعينها ويعوج بها اللسـان، مثل: الطـاء والقـاف والصـاد، ويجرى هذا على مستوى أجهزة الإعلام المسموعة - المرئية، ويضاف إلى هذا أثر اللافتات على اللغة، فهي

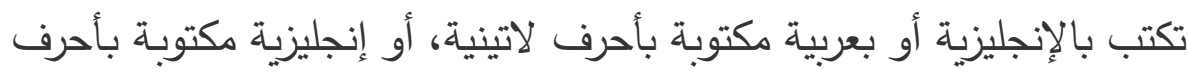

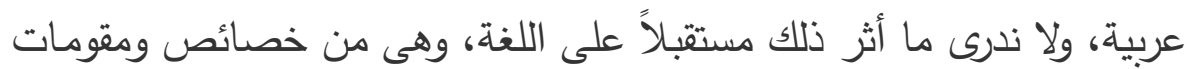

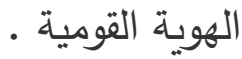
- تفضيل الكثيرين إلحاق أبنائهج بمدارس أجنبية أو بمدارس مصرية تهتم أساساً باللغة الأجنبية، وشيوع عدم الاهتمام بإتقان اللغة القومية أو التفوق فيها تدريسا

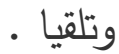

وجميع ما سبق يضعف الثعور بالذات القومية والحضارية، كما يؤدى إلى طمس ما يميز الهويـة القوميـة من معالم ومقومـات، وفى ظل هذا المنـاخ وبفعل تلك التأثيرات يكون لها تأثيراً واضحاً فى ضعف لهئ الهوية القومية . الفصل الثانى : دور الأنشطة التربوية فى تنمية الهوية القومية الأنشطة التربويـة لها دورهام فى إكساب وتتميـة قيم واتجاهـات التلاميذ الأخلاقيـة والاجتماعيـة والعلميـة والجمالية والنظريـة من خـلال المشـاركة في برامج تلك الأنشطة كما تعمل تلك الأنشطة على تفريخ طاقات التلاميذ وبالتالي خفض وتقليل المشكلات والسلوكيات الضارة بالمجتمع والبيئة المحيطة . وتتنوع الأنشطة التربوية وتتعدد، ومنها أهم أنواع الأنشطة التربوية :

$$
\begin{aligned}
& \text { 1- النشاط الاجتماعي • } \\
& \text { r- النشاط الثقافى } \\
& \text { r- النشاط الفنى . } \\
& \text { ع- النشاط الرياضى . } \\
& \text { (1) الأنشطة الاجتماعية: }
\end{aligned}
$$


انطلاقاً من مبدأ هام يؤكد على الإنسـان كائن إجتماعى بطبعـه فقد برزت أهميـة جماعات النشـاط الاجتمـاعي ودورهـا الفعـال فى تكوين الشخصية الاجتماعيـة للفرد، وتوثيق علاقته بالمجتمع الذى ينتمي إليه.

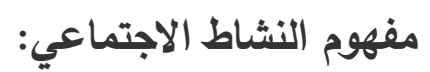
ويقصد به جميع الأنشطة التي يمارسها التلميذ داخل أو خارج المدرسة والتي من

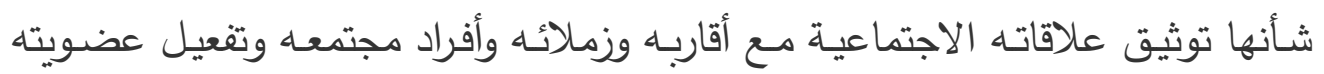

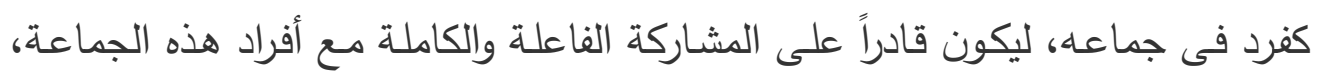
وتحمل تبعات هذه العضوية، كما يسهم فى تكوين شخصية التلميذ الاجتماعية السوية على اعتبـار أن الإنسـان لا يمكنهـ أن يعيش بفرده دون الاحتكالك بالآخرين ( إيمان،

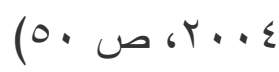

وتسعى الأنثطة الاجتماعية إلى تحقيق العديد من الأهداف، لعل أبرزها مـا يلي (Y)

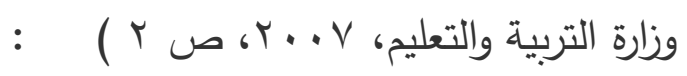
ا - مساعدة المتعلم كحالة فردية، وكعضو فى جماعـة كمواطن يعيش فى المجتمع، لتحقيق النمو المتوازن المتكامل لشخصيته، والاستفادة من الخبرات التعليمية إلى أقصى في هئه

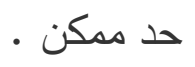

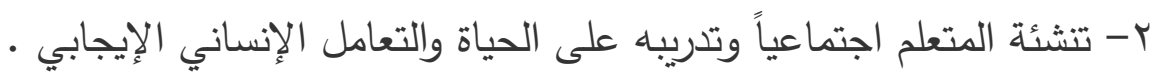

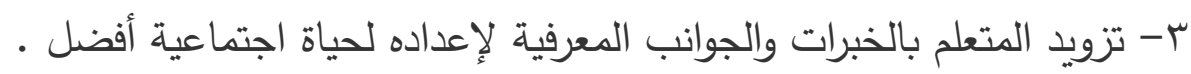

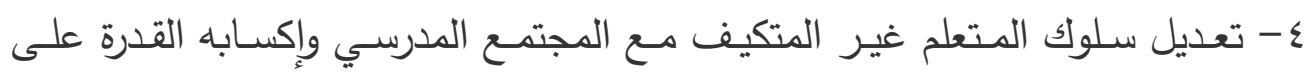

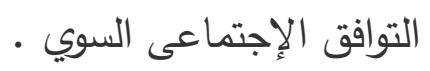
ه- التكامل مع المجتمع من أجل استثمار الطاقات البشرية المتاحة وحفزها على العمل

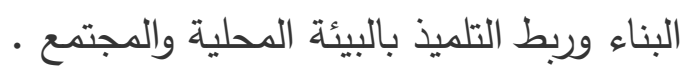
كما تجد الإشارة إلى أن النشاط الإجتماعى يضم عديدا من الجماعات مثل: جماعة ولئه الرحلات، وجماعة الخدمة العامة، وجماعة الاحتفالات المدرسية، والاتحادات الطلابية. وغيرها

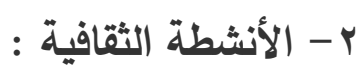


ويتضمن هذا النشاط كافة الخبرات والممارسات التي تسهم فى تكوين الإطار العقلي للتلاميذ من خلال تنمية الوعي الثقافى لديهم، وتزويدهم بالمهارات والمعلومـات التي تفيدهم فى تقديم المقترحات والمناقشات فى القضايا الفكريـة والثقافية التي تفرض نفئهـا فى الآونة الأخيرة سواء على المستوى المحلى أو الإقليمي أو العالمي .

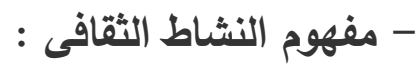

ويقصد بالنشاط الثقافى ألوان الممارسة العلمية التي يقوم بها التلاميذ بهدف تتمية

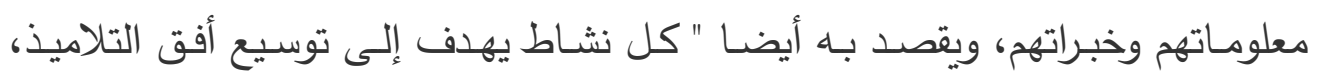

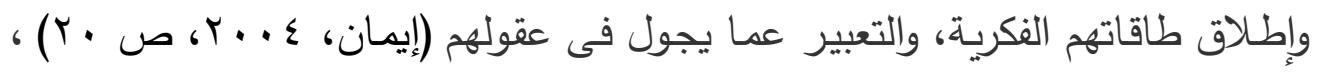
ويستقيدون منها فى التفكير العلمي، والمنطقي فى المواقف والمشكلات، وهو النشاط الذى يعطى أعضائه الفرصة لتكوين الخلفية العلمية والمعلوماتية التي تثار على الساحة ولهي أو حتى المشكلات التاريخيـة للاستفادة منها فى مشكلات حاضـرة أو مستقبلية سواء محلية أو عالمية. ويتمثل النشـاط الثقافى فـى عدة أنـواع مـن أهمهـا: الصـحافة المدرسـية ، الاذاعـة المدرسية ، المكتبة المدرسية .

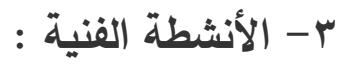

تتشـد التربيـة إلى بنـاء جميـع جوانبى شخصية الفرد الجسـية والعقليـة والروحيـة ويحتاج هذا البناء إلى تزويد الفرد بنوع الغذاء المناسب لكل جانب من هذه الجوانب، لكى تتمو وترتقى شخصيته الإنسانية، فكما يحتاج الجسم إلى الطعام، ويحتاج العقل إلى الفكر والإبداع، تحتاج الروح للفن الراقى كغذاء لها لتكتمل به شخصية الفرد . وتهدف الأنثطة الفنيـة إلى تحقيق عدة أهداف من أهمها (وزارة التربية والتعليم،

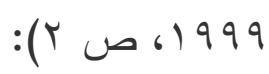
1- تذوق مواطن الجمال فى الطبيعة، وتنمية الحس الجمالي •

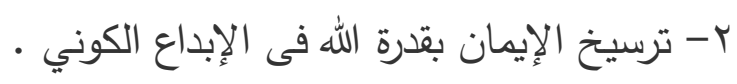

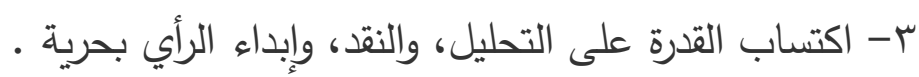
ع - غرس القيم الدينية والوطنية وتعميق حب الوطن والانتماء له والاعتزاز به . 
0- تشكيل وتربية الجوانب الوجدانية والانفعالية والخلقية للتلاميذ .

ج- تتمية مهارات التلميذ فى العزف على الآلات الموسيقية كل تلميذ حسب ميوله .

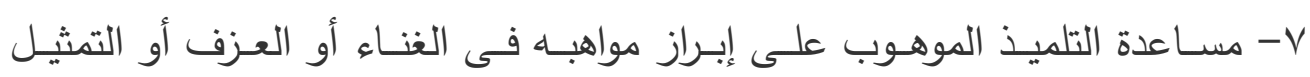
• والمسرح 1 - تتظيم الحفلات المدرسية فى الأعياد والمناسبات . 9- الترويح عن التلاميذ عن طريق الأغانى والأناشيد .

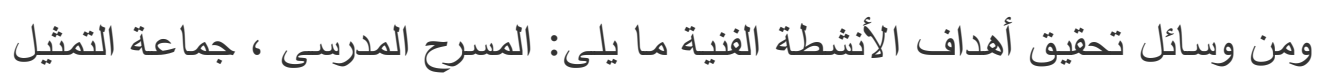
والمسرح

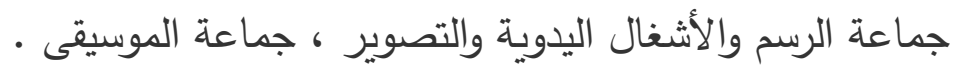
ع - الأنثطة الرياضية : ظهر الاهتمام برعاية جسم الإنسان أولاً حتى تضمن عقلاً سليماً متقتحاً قادرا على : على الإببداع والابتكار ، وهذا يعنى إحداث التوازن والتكامل فى الوقت نفسـه بين الجانبين

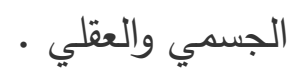
والنشـاط الرياضـي: يكسـب الفرد جسماً صـحياً، يعمل بنشـاط وحيويـة ويخلو مـن

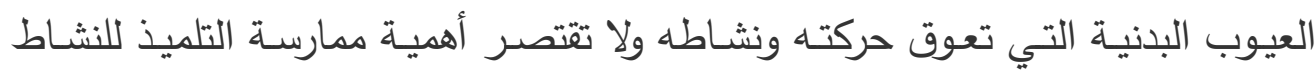
الرياضـي على صـته الجسمية فحسب بـل تمتـد لتشمل صـحته العقليـة والانفعاليـة والوجدانية مما ينعكس على صحته الجسمية مما ينعكس على إعداد أفراد قادرين على

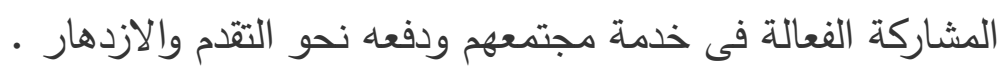

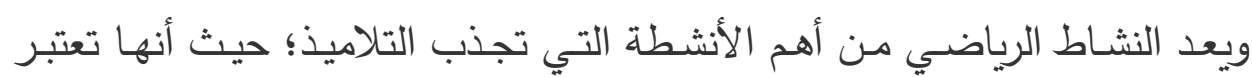

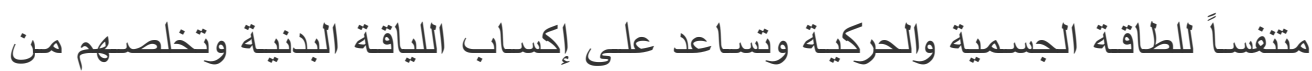
الاضطرابات النفسية، كما أنه أحد الوسائل الاجتماعية المقبولة لتفريغ الدوافع المكبوتة إلته

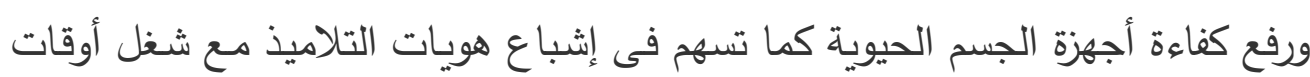

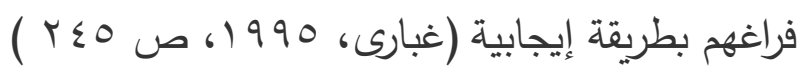


وتتمثل صـور النشـاط الرياضـي فى المعسكرات الكثـفية والرياضـية والمباريـات

والمسابقات والمهرجانات، ويحقق هذا النشـاط عدة أهداف من أهمها ( وزارة التربية

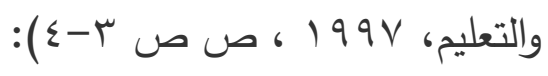

1- إتاحة الفرصة لأكبر عدد من المتعلمين للاشتراك فى الأنشطة الرياضية التي تقام

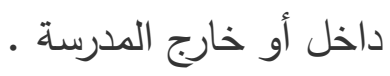

r - تنمية الروح الرياضية واحترام القانون والتعاون وإنكار الذات .

r - تعميق الولاء والانتماء للوطن - ت

ع- تتميـة اسـتعدادات المتعلمـين للعهـل التطـوعي ومشـروعات خدمـة البيئـة وتتميـة

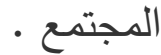

ه- التركيز على تتمية اللياقة البدنية العامة بين المتعلمين فى كافة المراحل التعليمية .

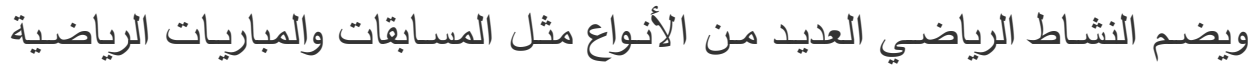

والمعسكرات واللقاءات والنشـرات الرياضية والمهرجانات الرياضية والبطولات الرسمية وتشمل الأنشطة الرياضية الألعاب المختلفة التي تمارس في المدارس مثل كرة القدم، والسلة، والطائرة، واليد، وتتس الطاولة، وألعاب القوى وغيرها ـ وتعد المسابقات والمباريات الرياضية من أبرز أنوع النشاط الرياضي التي يمارسها تلاميذ المدارس فى كافة مراحل التعليم • الاراسة الميدانية أولا ) أهداف الدراسة الميدانية تهدف الدراسة الميدانية إلى : ا- التعرف على الواقع الفعلى لدور الأنشطة التربوية فى تتمية الهوية القومية لتلاميذ المرحلة الاعدادية فى المدارس التجريبية الحكومية للغات .

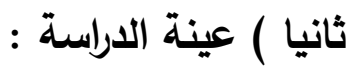
عينة عشوائية من طلاب وطالبات المرحلة الاعدادية والبالغ عددهم (^^ام) فردا بالمدارس التجربية الحكومية للغات فى محافظة قنا ومراكزها .

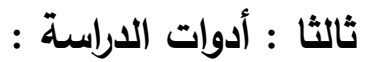


اعتمدت الدراسة على استبيان موجه الى تلاميذ المرحلة الاعدادية (بنين - بنات ) بالمدارس التجريبية الحكومية للغات بمحافظة قنا ـ واستخدم الباحث برنامج spss لحساب الانحراف المعيارى والمتوسط الحسابي والنسبة المئوية . ثانيا ) دور الأنشطة التربوية فى تتمية الهوية القومية . جدول (1)

\begin{tabular}{|c|c|c|c|c|c|c|c|c|}
\hline $\begin{array}{l}\text { E: } \\
E: ~\end{array}$ & E: & ف الانحرا & $\underline{E}$ & $y$ & $\sqrt{E}$ & نعم & الفقرة & ? \\
\hline V & $\vee q$ &.$v 1$ & T.TV & $r \varepsilon$ & 77 & 9. & تعمل الأنثطة الطلابية على إكساب & 1 \\
\hline$\varepsilon$ & 11 & .70 & $r . \leqslant r$ & 17 & vi & 94 & 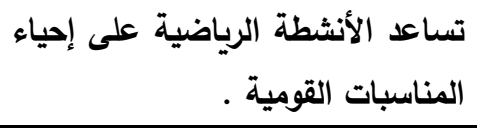 & r \\
\hline$r$ & NT &. .79 & Y. $\leqslant 7$ & r) & 07 & $1 \cdot r$ & تلمى المسابقات الرياضية فى نفوس الاعتزاز بعلم وطنهم . & r \\
\hline 7 & V9.7V &.$V Y$ & r.rq & ro & 7. & 90 & 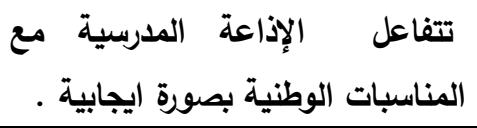 & $\varepsilon$ \\
\hline$\wedge$ & VA.TV & $.7 \mathrm{~V}$ & Y.ru & $r$. & $V T$ & $\wedge \varepsilon$ & تعرف الإذاعة المدرسية أخبار الوطن & 0 \\
\hline$r$ & س.r. &. .79 & r.o & $r$. & 0. & 11. & 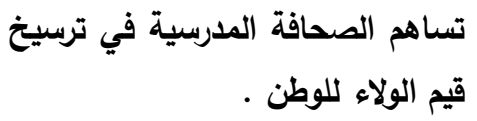 & 7 \\
\hline 1. & VV.rT &.$V r$ & T.MT & $r$. & $v$. & 9. & تغرس جماعة المكتبة فى نفوس الطعتل & V \\
\hline 7 & V9.7V &.$V T$ & r.rq & rt & ov & $9 V$ & تلطيح جماعة النشاط الثقافي الفرصة & $\wedge$ \\
\hline 0 & A..TV & .77 & $r . \Sigma Y$ & IV & VI & 94 & لتليح جماعة الخدمة العامة الفرصة & 9 \\
\hline Ir & $V \varepsilon$ & $\therefore$ Vo & T.MT & ro & $v$. & vo & تحرص جماعة الرحلات على تنظيم & 1 . \\
\hline
\end{tabular}




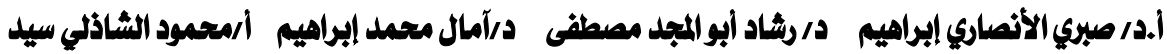

\begin{tabular}{|c|c|c|c|c|c|c|c|c|}
\hline & & & & & & & رحلات تعرف الطلاب بالمنشئات & \\
\hline 9 & VA &.$V Y$ & $T . T \varepsilon$ & ז & $T V$ & $\Lambda V$ & 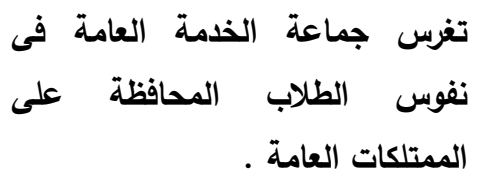 & 11 \\
\hline 10 & r9.r &. .1 & r.. & 01 & $T \varepsilon$ & 70 & تلنمى الاتحادات الطلابية فى نفوس قيم الديمقراطية التى تسود فى & IT \\
\hline $1 \varepsilon$ & $V \cdot .7 V$ &. .19 & T.IY & $\leqslant V$ & 70 & 71 & تطوير الثخصية الاتحادات الطلابية الطلاب فى لدية & $\pi$ \\
\hline $1 \pi$ & $V T$ &. .14 & r.19 & ru & 79 & $V T$ & تلتيع جماعة الرسم الفرصة للطلاب & $1 \varepsilon$ \\
\hline 11 & VI &.$v_{1}$ & T.YA & TV & vo & vA & تقداهم جماعة المسرح المدرسي فى النماذج الوطنية فى الأعمال & 10 \\
\hline 1 & AV.TV & . & Tז.T & 11 & $r$. & Tr & تبأهمية الملكية العامة الفنية الإحساس & 17 \\
\hline & VA & .10 & $T . T \varepsilon$ & $\varepsilon \varepsilon 1$ & $1.1 \mathrm{~V}$ & $1 \leqslant r r$ & البعد ككل & \\
\hline
\end{tabular}

من خلال النتائح الموضحة بالجدول رقم (1) اتضح ما يلى : اتفاق معظم أفراد العينة على عبارات هذا المحور بأنه متحقق بدرجة كبيرة وأن استجابات أفراد العينة

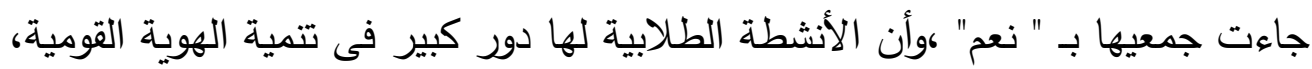
مما يؤكد أن هنالك اتجاهًا حقيقيًا نحو أهمية ممارسة الأنشطة ودورها التربوى الفعال. التوصيات

ا - توعية الأسرة والقائمون على التربية فى المجتمع بأهمية ممارسة الأنشطة التربوية r- التركيز والإكثار من الأنشطة التربوية الهادفة التى تخدم المجتمع والبيئة وتعمل على تتمية روح الانتماء والولاء الوطنى • 
r- إلزام الجهات المعنية بالأنشطة التربوية بإصدار نشرات دورية بأعداد كافية على التلاميذ توضح فيها نوعية الأنشطة والبرامج المختلفة التى تقدمها ـ لتراهي ع - الاهتمام بتوفير الملاعب والأجهزة والأدوات اللازمة لممارسة التلاميذ لمختلف أنواع

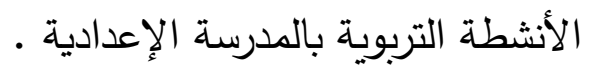

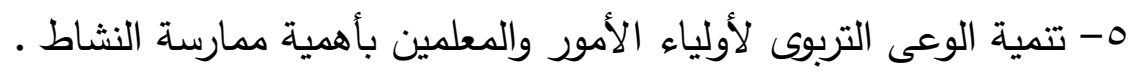
צ- العمل على تقويم جماعات الأنشطة التربوية المختلفة التى تقوم بالمساهمة الفعالة فى تقديم وعرض أنواع الأنشطة المختلفة طوال العام الدراسي تحت إثراف إدارة

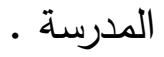

\section{المراجح?}

\section{المراجع العربية}

أولا ) الرسائل العلمية :

السيد سعداوى اسماعيل (991 (191) ـ الأنشطة المدرسية وعلاقتها بالقيم لدى تلاميذ

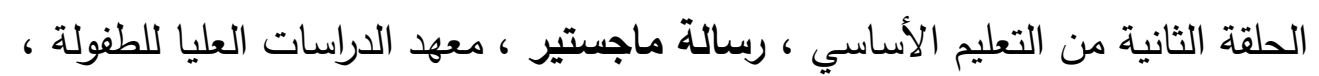

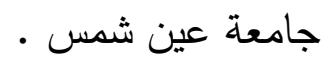

ايمان عبدالراضى ابو الحسن (ع . . ؟) ." التخطيط لاعم الانشطة المدرسية فى مرحلة

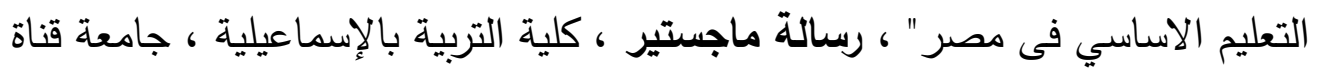

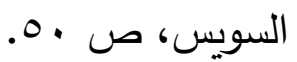


أسماء عبدالمنعم إبراهيم (9NVV ( ) ـ التغير الاجتماعى والقيم لاى فئات من الشعب

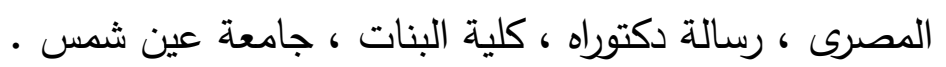
غادة السيد الوشاحى ( . . . F ). ممارسة الأنشطة التربوية فى التعليم الثانوى وعلاقتها

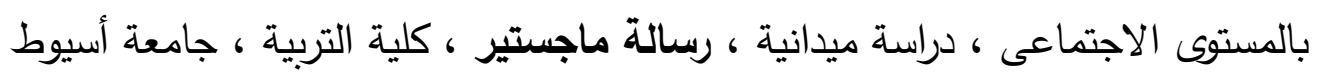

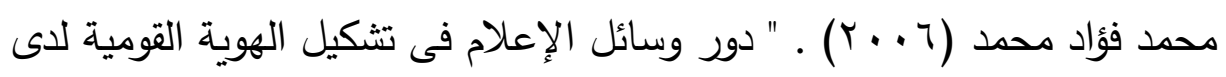
المراهقين " ، رسالة ماجستير ، معهد الدراسات العليا للطفولة ، جامعة عين شمس.

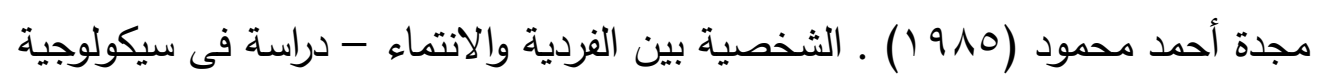
العلاقة بين الفرد والمجتمع ، رسالة دكتوراة ، كلية الاداب ، جامعة عين شمس • ثانيا ) الكتب السيد يس ـ الثخصية العربية ، بين صورة الذات والمفهوم الآخر ، القاهرة ، ( د ، ن .01 ص 1991، ( أحمد كامل الرشيدى (1991 () ) . بحوث ودراسات تربوية فى الميزان ، القاهرة ، المكتبة

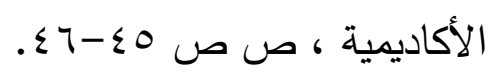
جابر عبدالحميد ، أحمد خيرى كاظم (1991 ) ) .مناهج البحث فى التربية وعلم

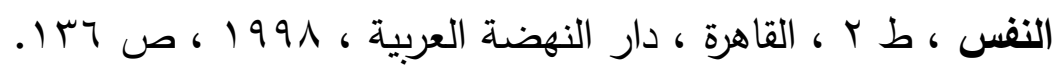

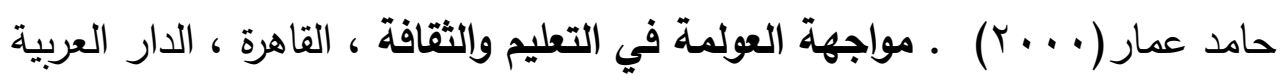
للكتاب ، ص اء سعيد إسماعيل (911 ( ) ) ـ الفكر التربوى الحديث ، القاهرة ، دار

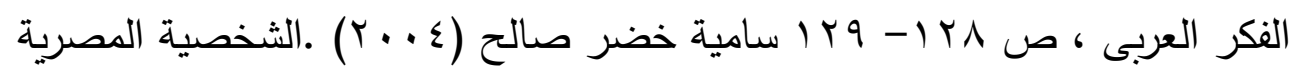

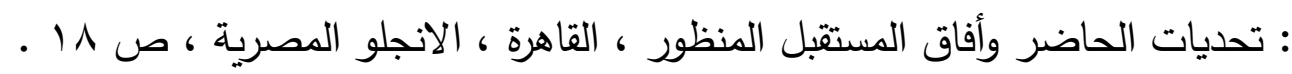
عدنان حسين (997 ( ) ) ـ العامل القومى فى السياسة المصرية ، بيروت ، دار الوحدة

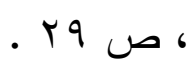
فاروق يوسف( 9 ( ) ) ـ السلام وأزمة الهويـة فى مصر ، القاهرة ، مكتبة عين شمس

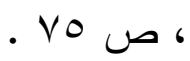


لطيفه ابراهيم خضر ( · . . †) .دور التعليم فى تعزيز الانتماء ، القاهرة ، دار الكتب ، ט

محمد نعمان جلال ، مجدى المتولي (99V ( ) ) . هويـة مصر ، القاهرة ، الهيئة

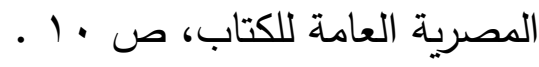
محمد سلامة غبارى (919 (19) ـ الخدمة الاجتماعية المدرسية ، الاسكندرية ، المكتب

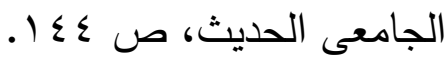
نبيل السمالوطى (9Av) ( I ) . بناء القوة والتتمية السياسية - دراسة في علم الاجتماع

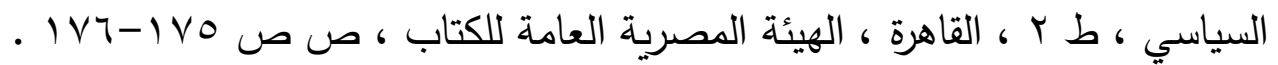
ثالثا ) المجلات والمؤتمرات ثريا احمد البدوى (ع . . r). "علاقة المضمون الامريكى بالهوية القومية للشباب

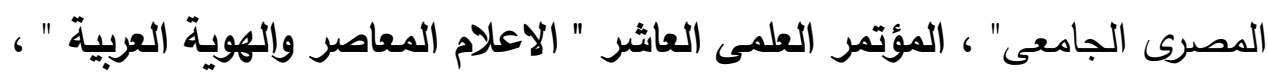

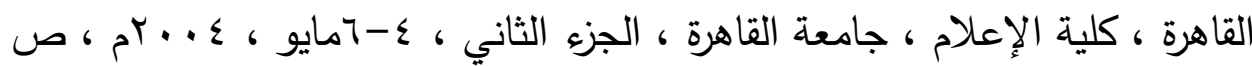
. org

درية السيد البنا (ع . . † ) ." واقع ممارسة الأنشطة التربوية الحرة بالمعاهد الأزهرية

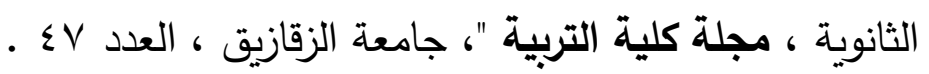
رزق حسن عبد النبى( س991 ) ) ـ "دور الأنشطة التربوية فى تنمية بعض القيم

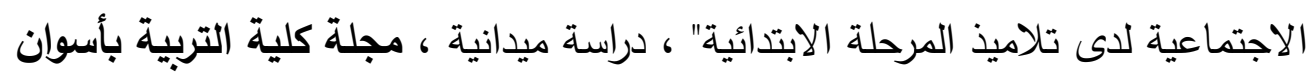

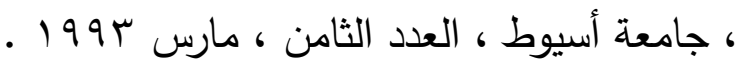

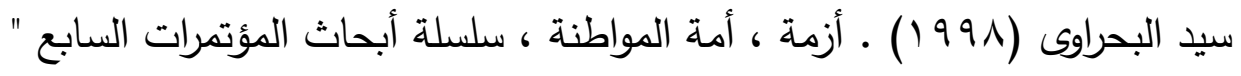

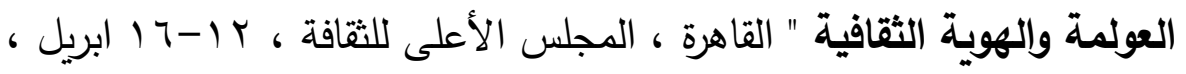

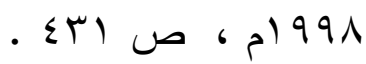
عايدة عباس واخرون (99 ( 99 ). تقويم الأنشطة التربوية بالمرحلة الابتدائية فى ضوء توصيات مؤتمر تطوير التعليم الابتدائى ، دراسة ميدانية ، المركز القومى للبحوث

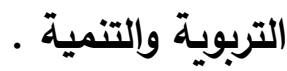


عصام توفيق قر (r . . r) ." دور الأنشطة التربوية فى مواجهة المشكلات السلوكية لطلاب المرحلة الثانوية" ، مجلة مستقبل التربية ، العدد هץ ، المجلد الثامن ، ابريل

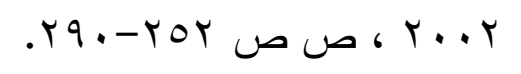

عبد الخالق عبد الله (999 (19) ـ" العولمة ، جذورها وفروعها وكيفية التعامل معها "،

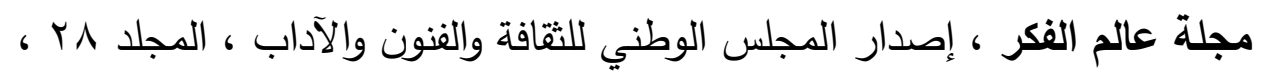

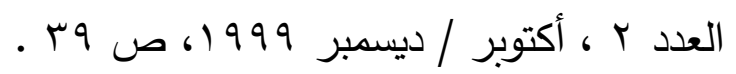
محمد حسنين عبده (7997 ) ." الأنشطة التربوية اللاصفية وتحقيق الوظيفة الاجتماعية للمدرسة مع التطبيق فى مدارس التعليم الأساسي بمحافظة الدقهلية" ، مجلة

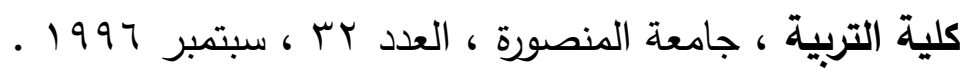

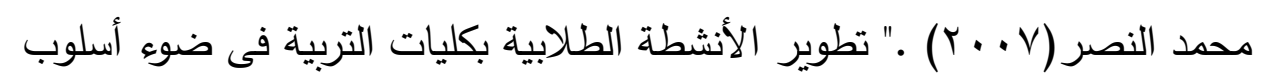
الجودة الثاملة ، جودة كليات التربية والاصدلاح المدرسي" ، المؤتمر العلمى الرابع

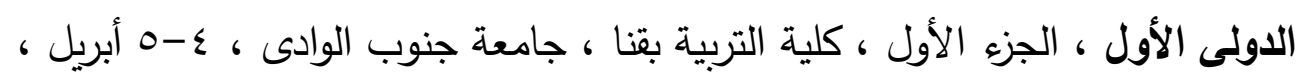

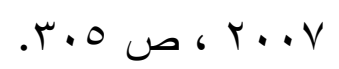

محمد على نصر (999 (19) ـ "إعداد المعلم وتدريبه بين العولمة والهوية القومية "، المؤتمر السنوي الحادى عشر " العولمة ومناهج التعليم "، القاهرة ، الجمعية المصرية ولية

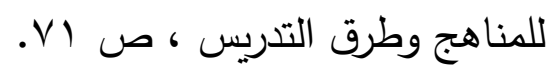

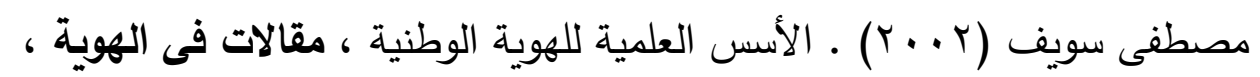

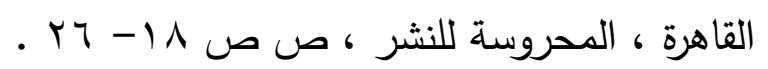
وزارة التربية والتعليم ـ الادارة العامة للتربية الاجتماعية ، خطة الادارة العامة للتربية

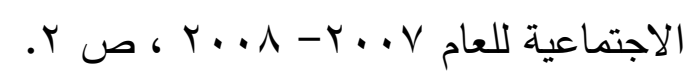
وزارة التربية والتعليم ـ الادارة العامة للتربية الثقافية والفنية ، ادارة المكتبات ، النشرة

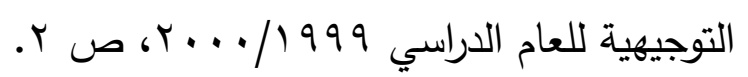

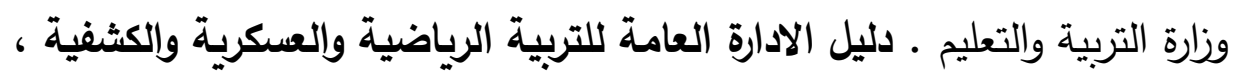

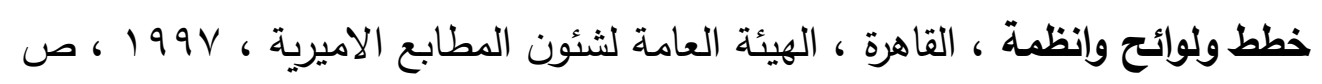
ص ص מ 


\section{المراجع الأجنيية}

Barakat Halim (1993) . Arab World : Society , Culture and State : Barkley University of California press, pp. 32-33.

Fischel and others(1995). " strategic tradoligy and giobalization a paradox or new paradigm Dalhousie, university of inda dissertation abstracts, p 163 .

Joseph,L.M,(2000)."School Extracurricular Activity

Participation as a Moderator in the Development of Antisocial patterns" , child Development,vol. (71),No .(2) , 2000 ,pp. 502516

Joseph,L.and others,(2003). promoting Interpersonal Competence and Educational Success through.Extra Curricular Activity participation,Journal of Educational psychology",vol.95, pp409-418.

keillor, Bruce \& Tomas Hult (1999). Afive - Country Study of National Identity , International Marketing Review ,vol . ( 16 ), No .( 16 ), p. $65 \quad$ Mulligan,Cail Maureen (2005). " The participation of Language Minortity families i formal School Environmental Activities",ph.D,University of Noter Dame,United States,2005

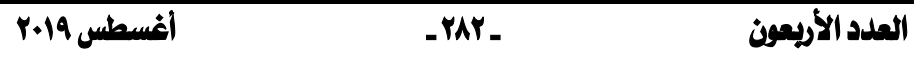


